Prikaz

Rukopis primljen 23. 8. 2017.

Prihvaćen za tisak 9. 10. 2017.

https://doi.org/10.22210/govor.2017.34.06

\title{
Iva Bašić
}

ibasic@ffzg.hr

Filozofski fakultet Sveučilišta u Zagrebu

Hrvatska

\section{XXXI. međunarodni znanstveni skup HDPL-a "Jezik i njegovi učinci". Rijeka, Hrvatska, od 4. do 6. svibnja 2017.}

Trideset i prvi međunarodni znanstveni skup Hrvatskoga društva za primijenjenu lingvistiku održan je u Rijeci od 4. do 6. svibnja 2017. godine. Konferencija se održava svake godine i okuplja članove HDPL-a, kao i druge istraživače, nastavnike i prevoditelje. S obzirom na to da brojni sudionici već godinama analiziraju na koji način jezik utječe na nas, ove je godine skup održan pod imenom Jezik i njegovi učinci (Language and its effects). Temom su obuhvaćena brojna zanimljiva područja unutar kojih se propitivao utjecaj jezika na društvo i ljudski um. Predsjednica Hrvatskoga društva za primijenjenu lingvistiku Diana Stolac najavila je da će skup biti šire tematike te da višeslojno obuhvaća sociolingvističke, psiholingvističke i kognitivnolingvističke poglede na jezik i njegove učinke. $\mathrm{Na}$ ovogodišnjem skupu HDPL-a sudjelovalo je više od stotinu izlagača u 17 sesija s više od 70 izlaganja. Sudionici su bili uglavnom iz Hrvatske, zatim iz bližega europskog okruženja, ali i izvan Europe.

Konferencija se održala na Filozofskom fakultetu Sveučilišta u Rijeci i svečano je otvorena 4. svibnja. Svakoga su dana predavanja bila podijeljena u tri ili četiri istovremene tematske sekcije, nakon kojih je bilo osigurano dovoljno vremena za neformalne razgovore sudionika i komentare na prethodna izlaganja. S obzirom na to da su dvorane u kojima su se održavala izlaganja bile vrlo blizu, bilo je moguće prisustvovati predavanjima iz različitih sekcija. Od ukupno četiri plenarna izlaganja, dva su održana prvoga dana, a sljedećih dana po jedno. Prvi je plenarni izlagač bio prof. dr. sc. Mario Brdar sa Sveučilišta Josipa Jurja Strossmayera u Osijeku s temom izlaganja "Neki metaforički i metonimijski efekti u zdravstvenom diskursu. Od spoznajnog prema društvenom". Budući da se zdravstveni djelatnici i korisnici 
zdravstvenih usluga često služe metaforama i metonimijama, posebice tijekom razgovora o medicinskim stanjima i daljnjim postupcima, istraživanjem se pokazalo da to pridonosi ublažavanju komunikacijskih barijera te pridobivanju povjerenja pacijenata u pridržavanju terapije. Predavač je naglasio da i metafora i metonimija mogu imati važnu društvenu funkciju u stvaranju bližih veza između zdravstvenih djelatnika i pacijenata. Također napominje da metafora umanjuje distancu između sudionika te da se sličan proces može uočiti i u uporabi različitih medicinskih eponima. Rezultati provedenoga istraživanja također ukazuju na to da su puni oblici eponima češći pri formalnim susretima, dok je uporaba eliptičnih, metonimijskih eponima prisutnija u neformalnima.

Druga je plenarna izlagačica bila viša lektorica prof. Danijela Trenkić sa Sveučilišta u Yorku s temom The effects of proficiency in the language of instruction on university students' academic achievement "Učinci stupnja znanja jezika poučavanja na uspjeh u studiranju". Izlagačica je predstavila rezultate provedenoga longitudinalnog istraživanja u kojemu je ispitana razlika u akademskom uspjehu stranih i domaćih studenata, ovisno o njihovim jezičnim vještinama. Rezultati ukazuju na velike i dosljedne razlike između analiziranih skupina studenata. Razlike su ponajviše izražene u poznavanju vokabulara engleskoga jezika te u brzini procesiranja informacija. Budući da provedena studija također ukazuje na povezanost jezičnih sposobnosti i razine akademskoga uspjeha na Sveučilištu, otvoreno je pitanje nepogodnosti s kojima se susreću strani studenti tijekom vlastite izobrazbe.

Treće je plenarno izlaganje održala prof. dr. sc. Henriette Hendriks sa Sveučilišta u Cambridgeu. Predavanjem pod naslovom Cognition versus linguistic typology as driving forces for language acquisition: Evidence from the expression of caused motion "Spoznaja nasuprot tipologiji kao pokretač usvajanja jezika: primjeri izražavanja uzročnosti" autorica je predstavila istraživanje provedeno na dječjem L1 i odraslom L2 u izražavanju kauzalnosti. Rezultati su pokazali da djeca, u usporedbi s odraslima, imaju jednako dobro razvijeno razumijevanje kauzalnih odnosa, iako ih odrasli bolje razumiju. Izlagačica je u predavanju protumačila kako se razvija shvaćanje kauzalnosti $\mathrm{u}$ ranom djetinjstvu te koju ulogu u tom procesu ima jezik. Naposljetku su ukratko analizirane razlike u izražavanju kauzalnih radnji kod djece i odraslih.

Posljednje je plenarno predavanje održao prof. dr. sc. Michele A. Cortelazzo sa Sveučilišta u Padovi. Predavanje s naslovom Quanto è vicino l'italiano letterario all'italiano (neo)standard? "Koliko je talijanski književni jezik blizak talijanskom 
(neo)standardu?" bilo je usmjereno na talijanski književni (neo)standard, a ispitani su čimbenici koji usporavaju ili ubrzavaju jezične promjene.

Prema već uobičajenoj tradiciji, na kraju prvoga dana skupa održano je predstavljanje deset knjiga: Applied Linguistics Research and Methodology: Proceedings from the 2015 CALS Conference, dviju urednica Kristine Cergol Kovačević i Sande Lucije Udier, Jezik kao predmet proučavanja i jezik kao predmet poučavanja, Zbornik radova sa znanstvenoga skupa HDPL-a 2016, urednica Diane Stolac i Anastazije Vlastelić, STRUNA - terminološki rječnik Instituta za hrvatski jezik i jezikoslovlje, Prijedlozi u hrvatskome jeziku - značenje, prostorni odnosi i konceptualizacija, autora Darka Matovca, Libar o jeziku Marka Uvodića Splićanina, autorica Dunje Jutronić, Marijane Tomelić Curlin te Anite Runjić-Stoilove, Uncovering English - Medium Instruction: Glocal Issues in Higher Education, autorica Branke Drljača Margić te Irene Vodopije Krstanović, New Insights into the Semantics of Legal Concepts Martine Bajčić, Dos heylike yidish vort: jidiš $i$ drugi jezici ortodoksnih Židova u New Yorku, autorice Gabi Abramac, Kognitivna gramatika hrvatskoga jezika (knjiga druga): sintaksa jednostavne rečenice, dvojice autora Branimira Belaja i Gorana Tanackovića Faletara te Towards the Professionalization of Court Interpreters and Legal Translators in the EU, dviju urednica Martine Bajčić i Katje Dobrić Basaneže.

Sekcije su pokrivale tematska područja jezičnih dodira (prevođenje, učenje i usvajanje jezika), dijalektologije (govori mladih govornika u manjim mjestima, utjecaji urbanih mjesta na učenje hrvatskoga), pragmatike (govorni činovi, teorije društvenih mreža), ortoepije (naglasne dublete, televizijski govor i izgovor) te brojne opće lingvističke teme. Iako su sve sekcije bile zanimljive, poseban je interes sudionika pobudila dijalektološka sekcija.

$\mathrm{Na}$ XXXI. HDPL-ovoj konferenciji sudjelovalo je više istraživača s Odsjeka za fonetiku Filozofskoga fakulteta u Zagrebu. Ana Vidović Zorić i Elenmari Pletikos Olof održale su izlaganje s temom "Učinak čitanja na glas i u sebi na pamćenje". Autorice su u radu istražile kako različiti načini čitanja i slušanja utječu na razumijevanje pročitanoga teksta i njegovo pamćenje, odnosno na kapacitet radnoga pamćenja. Damir Horga održao je predavanje s naslovom "Nefonemski glasnik [ə] u hrvatskom spontanom govoru". $\mathrm{U}$ radu se istraživalo trajanje, učestalost i distribucijske karakteristike nefonemskoga segmenta, $s$ obzirom na njegovo pojavljivanje u različitim vrstama artikulacijskoga zgloba te na stupanj formalnosti govorne situacije. Analizirano je 20 žena i 20 muškaraca u intervjuima na Prvom programu Hrvatskoga radija te na Studentskom radiju. Rezultati ukazuju na značajnu 
razliku u promatranim uzorcima govora. Iva Bašić i Zdravka Biočina održale su, u koautorstvu s Gordanom Varošanec-Škarić, izlaganje s temom "Prozodijski sustav Pražnica". Autorice su analizirale spontani govor 15 govornika koji su porijeklom iz Pražnica, koji tamo žive posljednjih deset godina i čija su oba roditelja iz toga mjesta. Govornici su se razlikovali po spolu i dobi. Rezultati istraživanja pokazali su da žene, neovisno o dobi, u većoj mjeri zadržavaju tradicionalno opisan prozodijski i vokalski sustav. Iva Bašić održala je i predavanje u koautorstvu s Dašom Grković s naslovom "Radio i televizija u naglašavanju". U radu je analizirano naglašavanje španjolskih posuđenica kod voditelja i spikera Hrvatske televizije. Rezultati provedenoga istraživanja ukazuju na češća odstupanja od naglasne norme kod voditelja. Odstupanja su se odnosila na ostvarivanje silaznih naglasaka na nepočetnim slogovima, neostvarivanje zanaglasnih dužina, ostvarivanje kratkosilaznoga naglaska umjesto kratkouzlaznoga i naglašavanje posljednjega sloga.

Budući da je i ova, XXXI. HDPL-ova konferencija bila iznimno dobro organizirana te da je uspješno prikupila brojne istraživače iz različitih zemalja, otvorila mnoge rasprave i nova istraživačka pitanja, možemo sa zadovoljstvom iščekivati iduću, XXXII. konferenciju koja će se, kako je najavljeno, održati u Rijeci od 3. do 5. svibnja 2018. pod naslovom Jezik i um. 